\title{
A narrow QRS gallop rhythm
}

\author{
Daniel Mol • Andrew Tjon Joek Tjien • Jonas S.S.G. de Jong
}

Published online: 28 January 2015

(C) The Author(s) 2015. This article is published with open access at Springerlink.com

A 59-year-old male patient was referred to our hospital for treatment of paroxysmal atrial fibrillation since 8 years, with frequent presentations to the emergency department for cardioversion. Previously, post-cardioversion sinus bradycardia was observed. After extensive discussion of the treatment options, the patient opted for a minimally invasive surgical pulmonary vein isolation. The ECG shown was recorded during ablation of the left-sided pulmonary veins (Fig. 1).

\section{Question}

What is the mechanism of this trigeminy rhythm?

You will find the answer elsewhere in this issue.

Open Access This article is distributed under the terms of the Creative Commons Attribution License which permits any use, distribution, and reproduction in any medium, provided the original author(s) and the source are credited.

Fig. 1 ECG recording during surgical pulmonary vein isolation

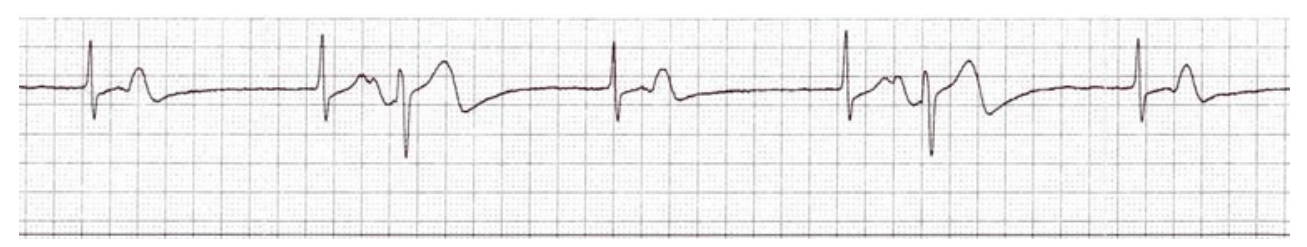

D. Mol · A. Tjon Joek Tjien · J.S.S.G. de Jong

Department of cardiology and cardiac surgery, Onze Lieve

Vrouwe Gasthuis,

Oosterpark 9,

1091 AC Amsterdam, The Netherlands

e-mail: d.mol@olvg.nl 